\title{
ETHNIC DIFFERENTIATION BY BLOCKS WITHIN CENSUS TRACTS ${ }^{1}$
}

\author{
James P. Allen and Eugene Turner \\ Department of Geography \\ California State University, Northridge \\ Northridge, CA 91330-8249
}

\begin{abstract}
How common is ethnic differentiation within census tracts and what types of tracts are most likely to exhibit this tendency? This research attempts to answer these questions with block data from the 1990 U.S. census for Los Angeles County. We measured non-random unevenness in ethnic percentage within tracts for twelve ethnic populations by means of an adjusted index of dissimilarity. Of the total of 300 sampled tracts, $48 \%$ showed statistically significant differentiation at the block level. Census tracts frequently mask details of ethnic patterning, especially in transition zones between larger ethnic settlement regions. Ethnic differentiation was most clearly related to block variations in housing type and cost, and tracts with fairly uniform housing were much less likely to show significant internal differentiation. Block-level differentiation was no greater for blacks than for some Asian groups and was average or low for non-Hispanic whites and people of Mexican origin.
\end{abstract}

Although the census tract has been by far the most convenient and widely used areal unit for analyzing the geography of metropolitan areas, it may mask the intricacies of ethnic distributions and be less homogeneous internally than is perhaps assumed. In this research we investigate intra-tract variations in ethnic percentages. We attempt to answer three related questions: (1) To what extent do blocks within census tracts show greater variation in ethnic group percentages than could be expected from random influences? (2) Which ethnic populations and types of tracts show the greatest ethnic differentiation by block? (3) Within tracts showing high levels of ethnic differentiation, are details of ethnic patterning associated with characteristics of specific blocks? For simplicity of expression we use the word "ethnic" to include social groups defined by either race or national origin, "Latino" to refer to the Mexican-origin population, and "white" to mean non-Hispanic whites.

Knowing the extent of intra-tract differentiation in ethnic composition would seem to be basic to understanding both ethnic distributions and the detailed spatial structure of contemporary urban areas. However, recent research has not examined such patterns within tracts. Micro-level research in geography has not been sufficiently detailed in terms of place or neighborhood to shed light on these matters. In macrolevel research, the numerous studies of residential differentiation in metropolitan areas, most frequently using factorial ecology or measuring residential segregation, have almost always employed census tracts themselves as the basic areal units-thus begging the question of the internal homogeneity of tracts. Sociologists have measured black-white segregation at the block level for many years (e.g., Taeuber and Taeuber, 1965), and one recent study examined the effect of parcel-size variations on city rankings of relative segregation, demonstrating that the areal unit of measurement can have a substantial effect (Lasus and Falk, 1990). 
Because blocks are the smallest areal unit for which any census data are available, our research utilizes those data. However, blocks themselves may well be differentiated internally. Although there may be variations in ethnic composition from one side of a block to another or even between groups of houses and apartments on the same street of a block, any investigation of spatial patterning at that scale is beyond the scope of this research.

The questions we raise, as well as questions concerning the areal units by which segregation should be measured, are examples of the modifiable areal unit problem in geography (Fotheringham and Wong, 1991; Openshaw, 1984). Research findings on that matter stand as a warning to geographers that area-based statistical results, particularly in multivariate analysis, are strongly influenced by the scale of the areal unit of measurement; but they have provided no guidelines for either selecting among already established units, such as blocks and tracts, or assessing the extent of internal differentiation within areal units.

Nevertheless, our goal is somewhat different from much of this related research, in that we seek to assess the extent of ethnic differentiation that is non-random. Studies of segregation, for example, are not concerned with eliminating random sources of spatial segregation because what is most important is the fact of areal differentiation, regardless of cause. In contrast, our research is designed to assess intra-tract differentiation as an indicator of the existence of urban settlement processes that are significant, but perhaps not well understood at this scale.

\section{REASONS FOR EXPECTING INTRA-TRACT UNEVENNESS}

Our exploration of block-level variations in ethnic proportion is premised on the existence of such patterning in the past, the compatibility of block-level differentiation with theory, and the likelihood that modern census tracts do not represent ethnically homogeneous areal units. Research on urban neighborhoods decades ago has frequently documented the existence of important ethnic differentiation over very small areas, frequently groups of two or three blocks or parts of blocks (e.g., Suttles, 1968; Thomas, Park, and Miller, 1921; Zorbaugh, 1929). Moreover, a 1934 blocklevel survey of 64 cities showed the significance of racial segregation at the block level at that time, when it found that $85 \%$ of over 100,000 blocks surveyed were exclusively white and another 5 percent were exclusively nonwhite (Hoyt, 1939). Similar ethnic neighborhoods, definable in terms of blocks and portions of blocks, also have been found more recently. Such patterns characterized an industrial-worker section of Denver in 1950 and in 1965 (Doeppers, 1967) and an older neighborhood of Philadelphia as of 1970 (Cybriwsky, 1978). All of these ethnic neighborhoods exhibited social boundaries and transition zones that would be blurred or lost if areal units much larger than blocks were used in mapping.

Intra-tract ethnic differentiation is consistent with theory based on individual consumer choice in the housing market (Cadwallader, 1988). Chain migration. followed by settlement close to friends or relatives who arrived earlier, still may be important for immigrants today (MacDonald and MacDonald, 1964). Contemporary immigrants, especially those less familiar with American culture, presumably also want to settle in the same apartment building or at least within a short walk of those whom they already know. In addition, ethnic composition often is an important part of 
people's neighborhood preferences (Clark, 1992). If people looking for an apartment or house to rent or buy make their decision partly on the basis of what appears to be the ethnic composition of individual apartment buildings or houses on the street and perhaps adjacent streets, the cumulative effect of this behavior can produce ethnic residential differentiation between blocks.

Variations in ethnic composition within tracts also can reflect different theory that stresses constraints on housing choice as a result of ethnic stratification and the role of institutions in residential differentiation (Bartlet et al., 1987; Cadwallader, 1988). Because ethnic groups may differ in their economic resources, ethnic differentiation can be expected to occur where housing within a census tract shows substantial price variation between blocks. Also, real estate agents, apartment managers, or lending agencies can, through selective advertising or other means, steer people either toward or away from housing in particular apartment buildings or streets (Tobin, 1987; Turner et al., 1991). There is every reason to think that the cumulative effect of such structural and institutional factors may well produce residential differentiation at the sub-tract level, just as they have done over larger areas.

Documentation for the 1990 census states that, "when first delineated, census tracts are designed to be homogeneous with respect to population characteristics, economic status, and living conditions" (U.S. Bureau of the Census, 1991a). Although it appears that differences in the ethnic composition of neighborhoods, as a component of the population characteristics criterion, frequently were used as a basis for originally defining tracts, it is unlikely that modern tracts define ethnically homogeneous areas (Cowgill and Cowgill, 1951). The difficulty of achieving and maintaining socioeconomic homogeneity was shown by the fact that tracts in New Haven, Connecticut in 1950 were as likely to be heterogeneous as homogeneous only a decade after initial tract delineation (Myers, 1954). Where tract boundaries have been stable over several decades, there has been ample time for changes in land use, decay of structures, new construction, and population movement to modify or completely erase whatever socioeconomic and housing homogeneity once existed within tracts. Where boundaries have had to be modified as metropolitan areas have grown, ethnic composition has not been listed as a criterion for delineation (U.S. Bureau of the Census, 1985), and it seems highly unlikely that it was used to redefine many tract boundaries in the 1970s and 1980s. For all these reasons, any assumption that modern tracts define ethnically homogeneous areas is unjustified.

\section{METHODOLOGY FOR MEASURING NON-RANDOM UNEVENNESS}

Our analysis uses sample tracts from the Los Angeles Primary Metropolitan Statistical Area (Los Angeles County). Because of its size ( 8.8 million population in 1990), ethnic diversity, and range of urban and suburban environments within its borders, Los Angeles is an appropriate laboratory for studying aspects of ethnicity in modern America. In the following paragraphs we describe the data, sampling procedures, and our use of the index of dissimilarity, which involves an adjustment to eliminate the random portion of block variations in ethnic percentage. 


\section{Block Data and Sampling Procedures}

Numbers of whites and nonwhites have been tabulated at the block level by the U.S. Bureau of the Census for the larger cities after 1940, but elaboration of ethnic categories and improvements in coverage since then have made block data increasingly useful. The 1990 census reported 22 specific racial groups at the block level, four Hispanic-origin categories, and Hispanic-origin cross-tabulations for the larger race groups (U.S. Bureau of the Census, 1991a). All block data have always been $100 \%$ count data; thus there is no sampling error. Blocks vary greatly in their populations, but in 1990 averaged about 120 residents in Los Angeles County.

In our use of block data, any undercount of nonwhite groups was assumed to be proportionate to the ethnic population of each block. Missing responses from census questionnaires could pose a problem, especially in block-level data, because the Bureau of the Census used a computer program to impute missing data based on the characteristics of a nearby household. In Los Angeles County, $4.8 \%$ of the race responses and $7.3 \%$ of the Hispanic-origin responses represent computer allocations rather than actual responses (U.S. Bureau of the Census, 1991a). Thus, ethnic percentages in some blocks, especially those having few members of the ethnic group, may have been in error because of wrongly allocated responses.

Because we wished to compare groups with respect to intra-tract differentiation, we randomly selected for each ethnic group a set of sample tracts from among all those tracts in which at least 200 members of the group lived. In order to determine how intra-tract differentiation varied according to the ethnic percentages in tracts, we stratified our sample tracts within three separate ranges of percentage composition.

Our main focus was on tracts where the specific group comprised from 15 to $45 \%$ of the total population, which we identified as the middle range. Because there were a number of tracts in which some Asian groups comprised up to about $45 \%$ of the tract population, the choice of this range enabled us to compare eight different groups in tracts where each was an important component of the population. In the high-range tracts, where groups represented 55 to $85 \%$ of the tract's population, only blacks, people of Mexican origin, and whites were found in a sufficient number of tracts to be sampled. Very low-percentage tracts had ethnic populations making up only two to six percent of the tract total, and several smaller ethnic groups now could be included. Although American Indians comprised over two percent of the population in seven tracts, that group was not included in this study because all tracts in the county contained fewer than 200 American Indians.

In the samples for middle and high ethnic percentage, each ethnic group was represented by 20 tracts. In the very low-percentage tracts, with fewer tracts containing over 200 members of the specific group, we sampled either five or ten tracts, depending on the population size of the group.

\section{The Index of Dissimilarity and Adjustment}

Ethnic differentiation is the degree to which individual blocks vary in their ethnic percentages from the ethnic percentage of the tract as a whole. Such intra-tract unevenness is best measured by the index of dissimilarity or $D$ (Appendix 1). 
However, an adjustment to the value of $D$ for each tract was necessary. Because $D$ measures departure from a standard of perfect evenness in ethnic proportion, it does not take into account the fact that a certain portion of unevenness simply is the result of randomness, the effect of which becomes much more pronounced with smaller populations and very low ethnic percentages. Our analyses were based on tracts averaging about 200 persons per block and included tracts that were very low in their ethnic percentage. Thus, it was necessary to reduce the calculated $D$ values for each tract by the proportion of $D$ that represented random unevenness for the specific ethnic percentage and average persons per block of that tract, as indicated by the expected value of $D$ calculated from the approximation to the binomial distribution. The expected $D$ for each tract then was subtracted from the originally calculated $D$ to produce an Adjusted $D$ score, which was then standardized to have a maximum of 1 , like $D$ itself (Appendix 1). This adjustment was especially important because we were not just comparing places with respect to unevenness, but were using $D$ values as indicators of the probability of non-random patterns and process at the sub-tract level.

Adjusted $D$ values then were tested for significance at the $95 \%$ level. This enabled us to determine the probability that the remaining unevenness in a tract could be accounted for by random processes that were a function of the number of blocks in the tract. Tables for the Kolmogorov-Smirnov test were used to determine if Adjusted $D$ for any tract exceeded the critical value needed to establish statistical significance (Table 1).

\section{METHODOLOGY FOR IDENTIFYING CHARACTERISTICS OF ETHNICALLY DIFFERENTIATED TRACTS AND BLOCKS}

In addition to examining variations in block-level differentiation among ethnic groups and in different percentage ranges, we wished to determine if there was any relationship between the degree of block-level differentiation and socioeconomic status. Because median household income has frequently been shown by factorial analysis to be an excellent indicator of status, we used correlation analysis to test the relationship between $D$ values (unadjusted) and median household income (U.S. Bureau of the Census, $199 \mathrm{lb}$ ) for sampled tracts in the $15-45 \%$ range. The analysis was restricted to these tracts because ethnic groups in the very low range were of too little influence in the average of their tracts' characteristics and the high-range tracts included only three ethnic groups. Cambodians were excluded from this analysis, as only five tracts had qualified to represent this population.

Also, mapping helped describe the geographical context of tracts with greater block-level differentiation and located specific blocks for field investigation. Significantly differentiated tracts were located and were the basis for selecting three multitract areas for block-level mapping. Figure 1 depicts those three areas (in rectangles) in relation to the pattern of predominant ethnic population. This helped us understand block-level differentiation within the broader pattern of ethnic regions. Figures 2, 3, and 4 show block-level ethnic percentages over three areas that contained substantial block-level variation. ${ }^{2}$

Field investigation also was used to better understand the nature of block-level differentiation. To make possible an exploration of specific blocks, we produced 
Tabie 1.-Intra-Tract Unevenness in Ethnic Proportion in Three. Percentage Ethnic Categories

\begin{tabular}{|c|c|c|c|c|c|c|}
\hline \multirow[t]{2}{*}{ Ethnic group } & \multicolumn{3}{|c|}{ Adjusted $D(\text { mean })^{\text {a }}$} & \multicolumn{3}{|c|}{$\begin{array}{c}\text { Percentage of tracts with Adjusted } D \\
\text { significant at } 95 \% \text { level }\end{array}$} \\
\hline & $\begin{array}{c}\text { Low } \\
(2-6 \%)\end{array}$ & $\begin{array}{c}\text { Middle } \\
(15-45 \%)\end{array}$ & $\begin{array}{c}\text { High } \\
(55-85 \%)\end{array}$ & $\begin{array}{c}\text { Low } \\
(2-6 \%)\end{array}$ & $\begin{array}{c}\text { Middle } \\
(15-45 \%)\end{array}$ & $\begin{array}{c}\text { High } \\
(55-85 \%)\end{array}$ \\
\hline Asian Indian & $.197(.303)$ & & & 20 & & \\
\hline Black & $.236(.352)$ & $.292(.343)$ & $.263(.318)$ & 50 & 65 & 40 \\
\hline Cambodian & $.669(.738)$ & $.392(.433)$ & & 100 & 100 & \\
\hline Chinese & $.257(.372)$ & $.170(.235)$ & & 70 & 25 & \\
\hline Cuban Origin & $.212(.341)$ & & & 40 & & \\
\hline Filipino & $.276(.389)$ & $.220(.275)$ & & 70 & 40 & \\
\hline Japanese & $.192(.320)$ & $.285(.370)$ & & 40 & 75 & \\
\hline Korean & $.351 \quad(.433)$ & $.289(.335)$ & & 80 & 45 & \\
\hline Mexican Origin & $.176(.323)$ & $.209(.261)$ & $.161(.235)$ & 40 & 35 & 30 \\
\hline Samoan & $.418(.508)$ & & & 60 & & \\
\hline Vietnamese & $.385(.498)$ & & & 100 & & \\
\hline \multicolumn{7}{|l|}{ White (Non- } \\
\hline Hispanic) & $.292(.399)$ & $.191(.255)$ & $.157(.222)$ & 50 & 30 & 30 \\
\hline All tracts & & & & 59 & 47 & 33 \\
\hline
\end{tabular}

Unadjusted $D$ (mean) in parentheses. In the high and medium percentage categories $N=20$ tracts for all groups except Cambodians, where $N=5$ tracts. In the low percentage category, $N=10$ tracts for the larger groups and $N=5$ for the smaller groups (Asian Indians, Cambodians, Cubans, Samoans, and Vietnamese).

working block-level maps of those tracts with the highest adjusted $D$ scores. Observation of those highly uneven tracts, as well as of portions of the three multi-tract areas mapped, often suggested differences in land use, housing type and quality, or other factors that seemed to be associated with the unevenness visible on each map. Our findings are presented in the following sections.

\section{PREVALENCE OF ETHNIC DIFFERENTIATION WITHIN TRACTS}

Two indicators of unevenness for the different groups are presented: the means of Adjusted $D$ values and the percentage of tracts with statistically significant Adjusted $D$ values (Table 1 ). Overall, $48 \%$ of the sampled tracts had statistically significant unevenness in ethnic percentages. This indicates that in almost half the tracts blocklevel patterning was the result of some real settlement processes rather than random variations. From the point of view of users of tract data, it may be encouraging to find that half the tracts were not differentiated ethnically at the block level and could be considered internally homogeneous. Moreover, ethnic differentiation at the block level did not produce a high degree of unevenness. This is shown by the fact that the means of adjusted $D$ scores were almost all low or moderate (below .600).

Although block-level differentiation was widespread across the range of ethnic percentages, it was most evident in the very low percentage tracts, where $59 \%$ of the 
sampled tracts were significantly uneven. This suggests that small specific ethnic populations embedded in tracts in which another group is numerically dominant are particularly likely to show block-level differentiation. However, the numerically dominant group itself may be less likely to show the same differentiation because its distribution is contrasted with the aggregated total of individuals of varied ethnic identity who are not part of the dominant group. Thus, urban geographers should be particularly conscious of the possibility of intra-tract differentiation among smaller ethnic populations.

\section{GROUP DIFFERENCES IN BLOCK-LEVEL DIFFERENTIATION}

In both the low-and middle-percentage tracts, block-level differentiation was the highest for Cambodians, many of whom arrived in the early 1980s as refugees. In the low-percentage range, Samoans and Vietnamese ranked next in their Adjusted $D$ means, and Koreans showed relatively high levels of block differentiation in both lowand middle-percentage tracts. Among other Asian populations, results were less consistent. Japanese were much more differentiated within tracts in which they represented 15 to $45 \%$ of the population, whereas Chinese and Filipinos showed greater block-level unevenness at the very low percentages.

The inconsistent Adjusted $D$ values and rankings of Asian ethnic groups at low and moderate percentages make the findings on specific groups difficult to understand. If the assimilationist model of immigrant concentration and dispersal (Massey, 1985; White, 1988) is applied at the scale of individual blocks, we would expect a greater tendency to cluster geographically (and thus higher $D$ values) among immigrants and especially more-recent immigrants than among U.S.-born members of ethnic groups. The data did not permit such distinctions, but it seems unlikely that ethnic enclaves for the larger Asian populations-Koreans, Chinese, and Japanese-would be so highly localized as to be defined in terms of individual blocks rather than much larger areas. On the other hand, the greater intra-tract differentiation among generally less acculturated and poorer groups-Cambodians, Vietnamese, and Samoans-in comparison to Asian Indians would be predicted from the model. There probably were highly intricate patterns of chain migration and family-linked settlement among Cambodians and other recent arrivals that our data and methods simply were unable to probe.

For blacks, block-level differentiation in the middle-percentage range was comparable to that of Japanese and Koreans, but higher than for Latinos (Table 1). In very low-percentage tracts, black unevenness was less than it was for half the Asian groups. Blacks simply did not show at the block level the exceptionally high level of unevenness that almost always has been found in comparative studies of black, Latino, and Asian segregation at the tract level (Harrison and Weinberg, 1992; Massey and Denton, 1989). These comparative findings suggest that the segregation of blacks is more pronounced and significant over the much larger areas of groups of tracts than it is within tracts, where it is on a comparable level with that of Asians. 
TABie 2.-Correlations of Intra-tract Unevenness $(D)$ WITH MEDIAN HOUSEHOLd INCOMEa

\begin{tabular}{lc}
\hline \hline Ethnic Group & $r$ \\
\hline Black & $.48 \mathrm{I}^{\mathrm{h}}$ \\
Chinese & .050 \\
Filipino & .124 \\
Japanese & $-.771^{\mathrm{c}}$ \\
Korean & $-.573^{\mathrm{c}}$ \\
Mexican Origin & $.466^{\mathrm{b}}$ \\
White (Non-Hispanic) & -.326 \\
\hline
\end{tabular}

\footnotetext{
Pearson correlations for 20 sampled tracts for each group, with groups representing between 15 and $45 \%$ of total population in each tract. Income data are based on total tract households as reported in STF3 (12.7\% sample data).

'Indicates correlation is significant at the $95 \%$ confidence level.

'Indicates correlation is significant at the $99 \%$ level.
}

Both Latinos and whites show low or moderate levels of differentiation within their sampled tracts. The result for whites, especially in comparison to most Asian groups, may seem surprising if one believes that whites are the only group with strong preferences about neighborhood ethnic composition. This is related to relative segregation levels as measured in terms of tracts over the entire metropolitan area. The index of dissimilarity for black-white and black-Japanese segregation in 1990 is the same (.73) and lower than that for black-Korean (.78) or black-Chinese (.80) segregation (Allen and Turner, forthcoming). Moreover, recent research in the Los Angeles area showed that all the ethnic groups (whites, blacks, Latinos, and Asians) tended to move and settle in those tracts where their group was dominant, thus expressing some degree of avoidance of the other groups (Clark, 1992). Although whites generally preferred neighborhoods with higher percentages of their own group, the fact that differences between groups in neighborhood composition preferences were not striking is consistent with our finding that whites did not show a high degree of intra-tract unevenness.

\section{ECONOMIC STATUS AND LOCATION OF HIGHLY DIFFERENTIATED TRACTS}

Correlation analysis showed that unadjusted $D$ values of tracts were significantly associated with median household income for some of the ethnic groups, but not for all (Table 2). Blacks and people of Mexican origin showed significantly greater differentiation within tracts with higher incomes, whereas Japanese and Koreans were more differentiated in those tracts where their incomes were lower. Because blacks and Latinos generally have lower income levels than whites and Asians, these results suggest that block-level ethnic differentiation has an important economic component that reflects differences in resources between ethnic groups.

Mapping shows that tracts with greater block-level differentiation among Japanese and Koreans and among blacks and Latinos tend to lie in a broad ethnic and economic 


\section{Sampled Tracts and Predominant Ethnic Group Southern Los Angeles County}

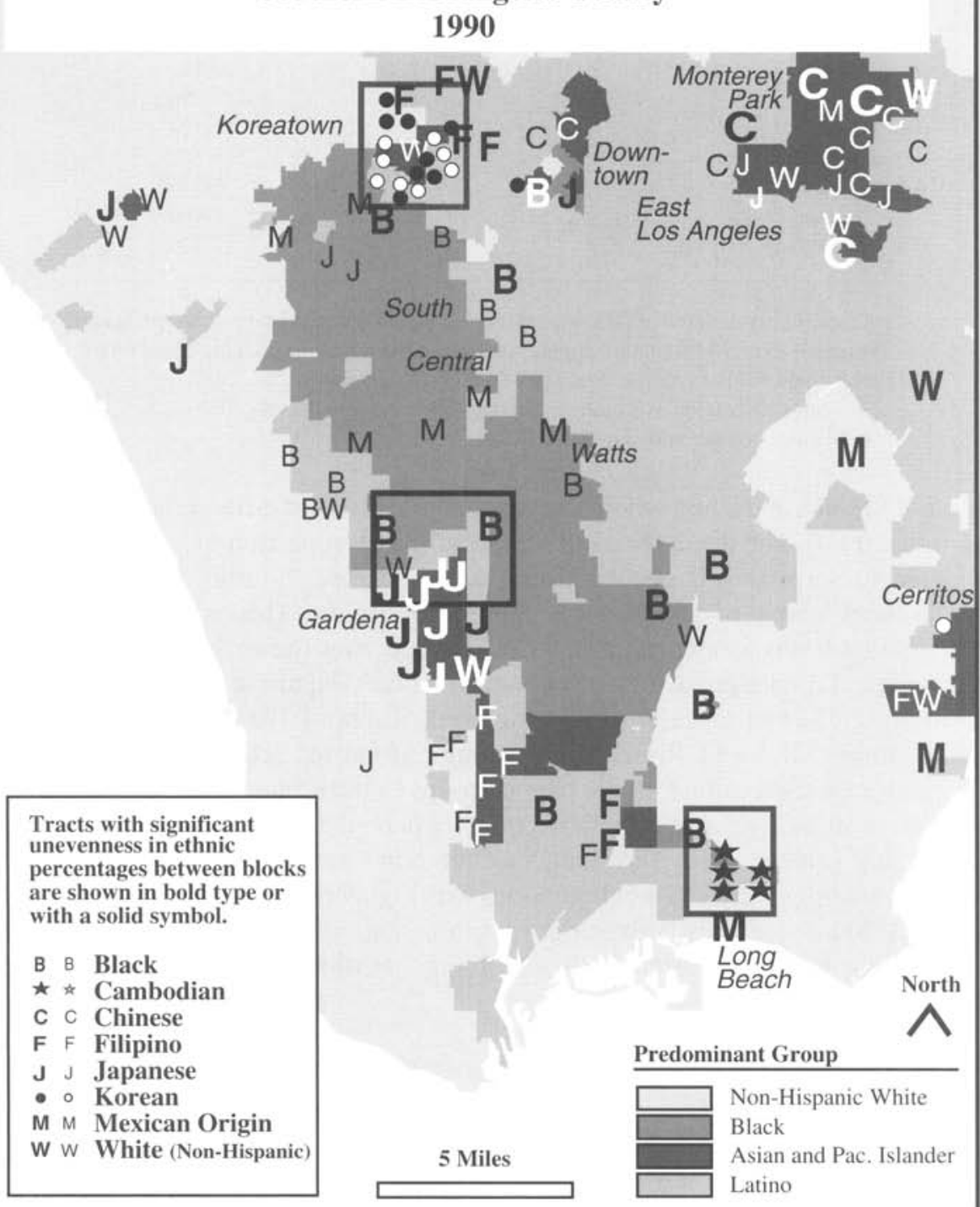

Fig. 1. Sampled tracts in relation to the predominant (numerically largest) of four major ethnic populations. Only those sampled tracts with ethnic populations representing 15 to $45 \%$ of the total tract population are shown. For each of the eight ethnic groups, the larger type or solid symbol indicates a tract whose block-level ethnic differentiation was found to be statistically significant. Rectangles locate the three areas shown by the block-level maps (Figs. 2, 3, and 4). This map covers only the southern portion of the county, where sampled tracts and significant differentiation were more common. 
transition zone between the extreme poverty of South Central Los Angeles and outlying areas (Fig. 1). The largest Japanese and Korean settlements in Los Angeles County (in Gardena and Koreatown, respectively) lie on different sides of the zone of greatest poverty. Until the 1980 s, South Central was predominantly black, but enough Mexican immigrants crowded into the area that by 1990 the eastern side (from Watts northward) was predominantly Latino. Because Japanese and Koreans have higher incomes than blacks and Latinos, block-level ethnic differentiation may well be partly a function of the greater variation from block to block in housing costs within this transition zone.

On the other hand, hardly any sampled tracts lying entirely within the broad, poor South Central region showed significant internal differentiation of either blacks or Latinos (Fig. 1), despite invasion and succession and the cultural differences between those groups. Housing throughout the area has been characterized by older and modest single-family dwellings without the in-filling of apartments and condominiums so widespread elsewhere in areas of higher income. Although competition and tensions between blacks and Latinos have been quite evident (Johnson and Oliver, 1989), the absence of intra-tract unevenness in South Central may well have been the result of a general uniformity of housing. In any case, South Central is a demonstration that neither poverty, nor invasion and succession, nor tensions between groups necessarily results in ethnic concentrations at the block level.

\section{INTRA-TRACT PATTERNING IN THREE MAPPED AREAS}

Mapping of three ethnically diverse areas aids in our understanding of the nature of block-level ethnic patterning, especially when combined with field investigation and, in some cases, statistical analysis. Areas were chosen to include some sampled tracts because their Adjusted $D$ values were already known. We visited the areas mapped in an attempt to find observable differences in land use or housing type that might help us understand the patterning in ethnic percentage. Where the areas mapped include sampled tracts that had unadjusted $D$ values above .350 , we also report results of block-level correlation analysis of those tracts between percentage ethnic and the two economic variables (median home value and median contract rent) available from the STF1B file (U.S. Bureau of the Census, 1991a) where these were statistically significant at the $95 \%$ level.

\section{Koreatown}

Figure 2 clearly shows that patterning of percent Korean bears no relationship to tract delineation. Because several of the tracts shown also are among the sampled tracts, this map is particularly useful in depicting visually the geographical appearance of tracts with non-random block-level unevenness in comparison to other tracts whose unevenness was not significantly different from random. To illustrate, the greatest block-level unevenness in percentage Korean in sampled tracts was found in tracts 2111,2114 , and 2131 (Adj. $D=.454, .433$, and .445 , respectively), whereas tracts with the least block-level differentiation (and not statistically significant) were 2126 and 2127 (Adj. $D=.218$ and .169 , respectively). 


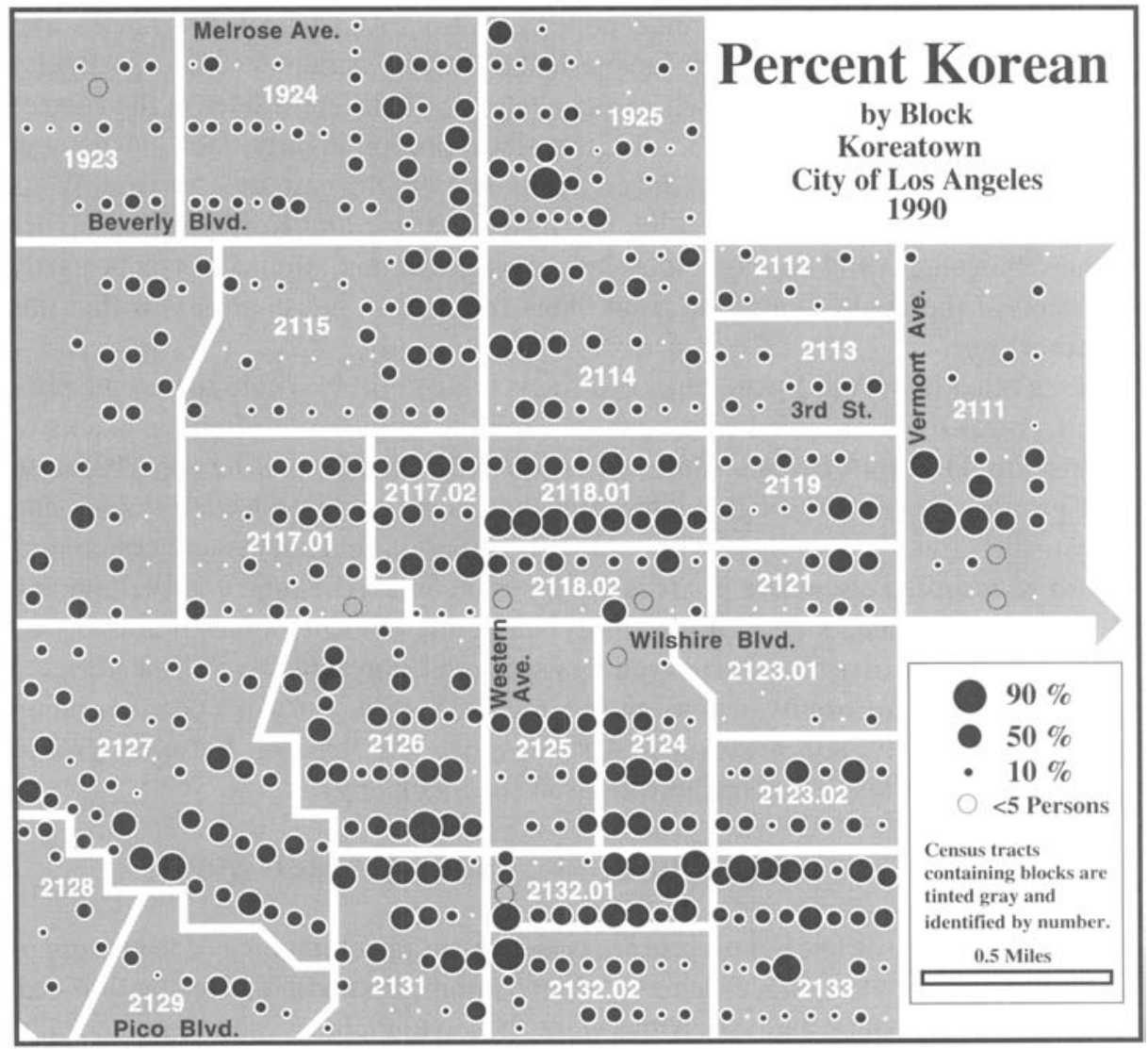

Fig. 2. Block variations in percentage Korean within Koreatown, shown by block centroids. Percentage Korean varied from $81 \%$ in the southwestern quarter of tract 2111 to $0 \%$ in many blocks, as indicated by the smallest white dots without black centers. Blocks averaged 248 persons, but two blocks contained no residents. Portions of tracts without block centroids usually indicate very large blocks or parks.

Koreatown represents a transition zone between lower economic status on the east and higher status on the west. Ethnically it also lies between areas dominated by whites on the west, blacks on the southwest, and Latinos on the east and southeast. For example, the west side of tracts 2115 and 2117.01 is part of the Hancock Park area, where most of the very expensive and elegant single-family homes were occupied by whites. However, on the eastern and southern margins of Koreatown those blocks with low percentages of Koreans were apt to contain older, poorly maintained apartments. This also was found inside Koreatown, such as in tract 2132.01 and in the two blocks at the northwest and southwest corners of tract 2114 .

On the other hand, the significant block-level differentiation in percentage Korean found in tract 2131, on the southwest side of Koreatown, showed no significant correlation with median rent or home value. However, field observation identified much higher percentages of blacks in a three-block area of more elegant and architecturally distinctive homes near Pico Boulevard. These blocks changed from all white to predominantly black in less than two years (1946-1948), during which time 
invasion by black and a few Asian families prompted an exodus by all except three white families (Chen, 1952).

Statistical analysis confirmed many of the field observations. Reflective of transitional locations on the fringe of Koreatown, correlation analysis showed significantly higher percentages of Koreans associated with the higher-rent blocks of tract 2111 on the east side of Koreatown, where Latinos were apt to occupy the lower-rent blocks. Conversely, in tract 2115 on the Hancock Park side of Koreatown, where most people were homeowners, blocks with low percentages of Koreans were significantly associated with higher median home values.

Commercial corridors with office buildings and new Korean-built shopping malls line Vermont and Western Avenues (Fig. 2) as well as Olympic Boulevard, a major artery not shown but trending east-west through tract 2132.01 . However, these are not expressed on the map in any consistent differentiation of percentage Korean. This presumably is because of the narrowness of these commercial strips and their lack of effect on the quality of the adjacent residential areas. An exception to this appears to be the prestigious and much older Wilshire Boulevard, whose influence extended into the adjacent residential side streets and whose apartment buildings remained mostly occupied by whites.

\section{Gardena Area}

Figure 3 shows the nature of block-level differentiation in the suburban fringe of the largest black residential concentration in Los Angeles County. The area was first built up with modest tract homes in the late 1940s and 1950s. In 1960 nearly all these new suburban residents were white except for some Japanese, whose major concentration was just off the southeastern side of this map. At that time the contiguous black settlement of South Central included only the two tracts at the upper right of the map, with blacks comprising less than one percent of the population west of Vermont Avenue. The next three decades saw black expansion westward and white flight from all except the southwestern portion of the mapped area and resegregation as predominantly black. In the 1980 s came the newest group, Latinos, who tended to settle in the less expensive housing, especially near industrial areas.

Those tracts with little if any block differentiation had a uniformity of housing, epitomized by the attractive and well maintained single-family homes in tract 6026 and in the most populated sections of tracts 6027 and 6028. In tract 6026 the only blocks with much lower percentages of blacks were those along the tract's southern and eastern sides, all of which are characterized by apartment complexes. However, the remainder of all these tracts showed little areal variation in either housing or percentage black.

In contrast, tracts with significant block-level differentiation generally had internal variations in land-use or housing characteristics, as in sampled tract 5409.01 (upper right portion of Fig. 3). There the percentage of Latinos was higher in blocks containing very small homes on the south side of the tract, but blacks occupied the larger and better maintained homes to the north. In tract 6034 (bottom of map) field investigation revealed that the strongly Japanese blocks contained single-family houses almost exclusively and were not adjacent to major thoroughfares and com- 


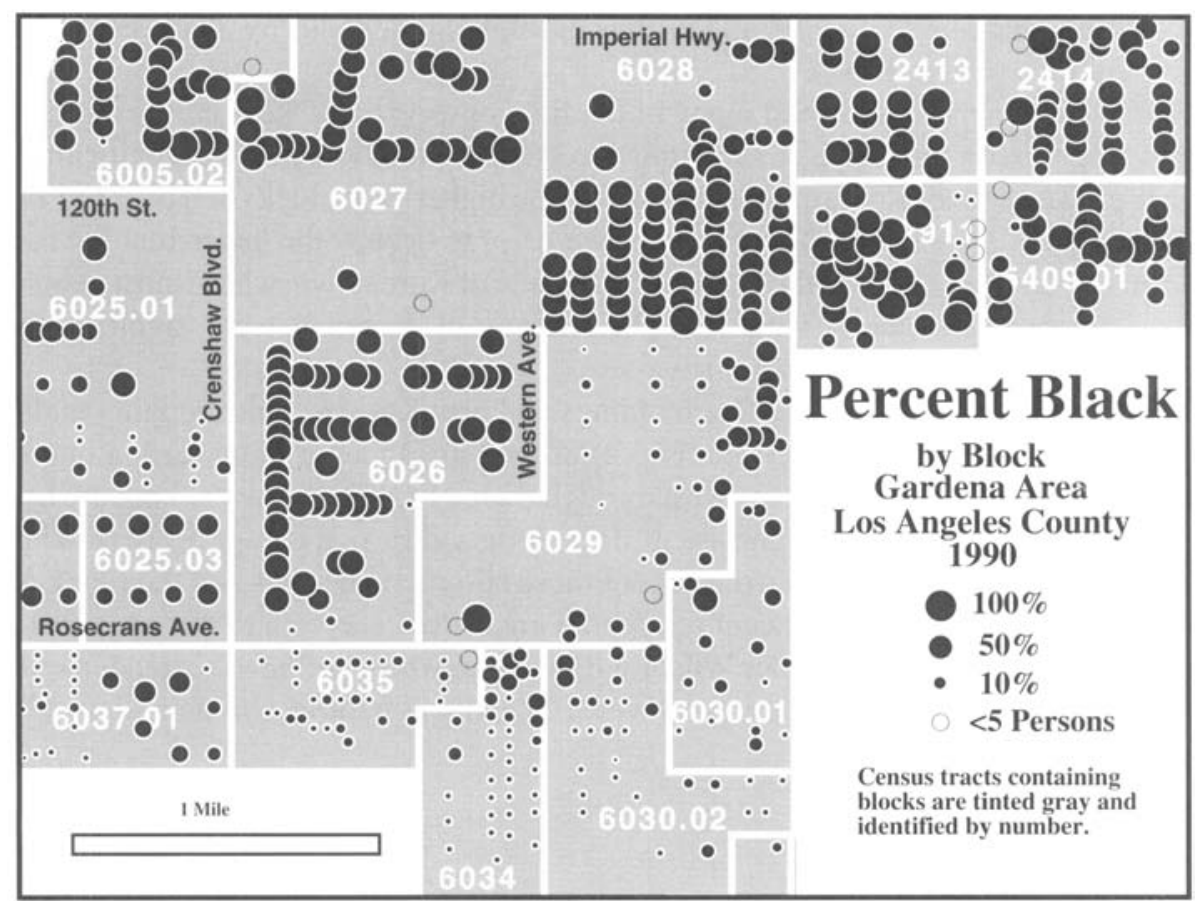

Fig. 3. Block variations of percentage black, shown by block centroids, in and near Gardena. Blocks averaged 149 inhabitants, but one block had no inhabitants. Percentage black varied from $100 \%$ in 31 blocks to $0 \%$ in many blocks. Portions of tracts without block centroids are usually industrial or warehousing areas.

mercial centers, and block-level correlation showed that higher Japanese percentages were significantly associated with higher home values. This was in contrast to the much greater number of apartment buildings in the north end of the tract, where black percentages were higher. Farther away from the Asian concentration, tracts 6025.01 and 6037.01 (left side of map) were similar in that blacks tended to live in blocks with apartment buildings, whereas whites and Latinos more typically occupied the blocks with single-family houses.

\section{Long Beach Area}

Figure 4 portrays the exceptionally high level of block-level differentiation in the most important areas of Cambodian settlement. Most of the people who established Long Beach as the largest Cambodian settlement in the United States had entered this country as refugees beginning in the late $1970 \mathrm{~s}$. They moved into an ethnically mixed area and carved out their geographical niche between the long-established black concentration in tracts 5733 and 5752 and the mostly white population near East 7 th Street.

During the 1980s, Cambodians, together with immigrant Vietnamese and Chinese, crowded into apartment buildings, renovated scattered shops, and built several malls 


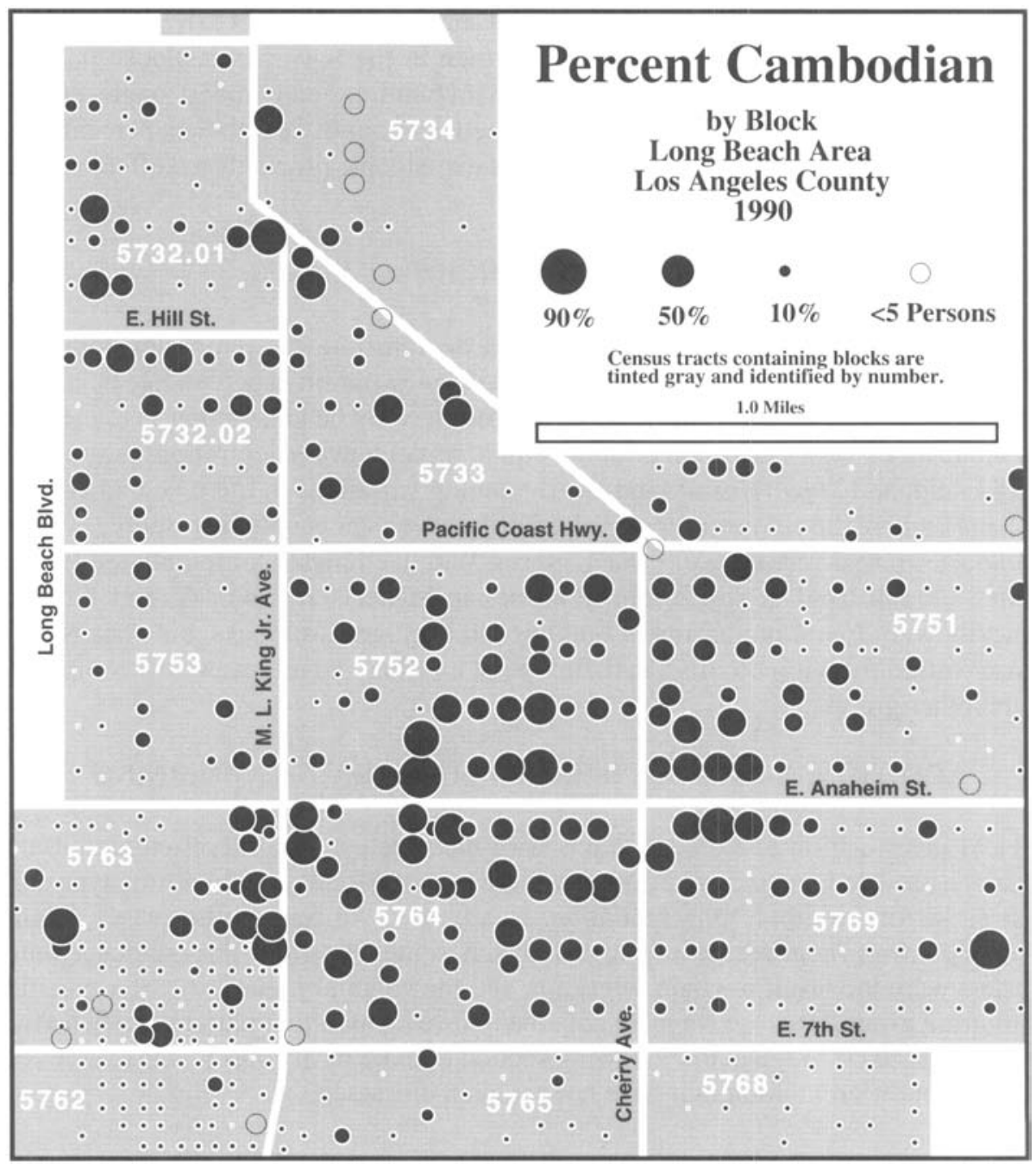

Fig. 4. Block variations in percentage Cambodian, shown by block centroids, in Long Beach area. Blocks averaged 149 inhabitants, but two blocks had no inhabitants. Percentage Cambodian ranged from $90 \%$ in one block on the southern edge of tract 5752 to $0 \%$ in many blocks.

along East Anaheim Street, returning prosperity to that older and previously declining part of Long Beach. By 1990, Cambodians, over $90 \%$ of whom were renters of apartments and homes, comprised a quarter of the population in tracts 5752 and 5764. The bottom half of the map shows that Cambodians tended to live in the portions of tracts closer to their settlement focus. Thus, Cambodians have tended to live in the western half of tracts 5751 and 5769 and in the eastern half of tract 5763.

Block-level correlations between percentage Cambodian and median rent were significant and interpretable in terms of economic-status variations among the tracts. Cambodians lived in blocks with higher rents in tract 5733, a relatively poorer tract; but in the generally higher-priced rentals of tracts 5751 and 5769, Cambodians 
occupied those blocks with lower rents. Thus, Cambodians were apt to reside in blocks of low to moderate economic status rather than in the lowest-cost blocks in their settlement area. Two- and three-story apartment buildings and modest single-family houses are intermixed throughout the mapped area, and Cambodian percentages seem too intricately and sharply variable to be explainable primarily by differences in housing type or cost.

\section{SUMMARY OF EVIDENCE FROM MAPS}

The three areas mapped were selected to demonstrate the patterning found in ethnically diverse areas with substantial block-level variation in percentage ethnic. In these situations block-level ethnic patterning often could be understood as related to: (1) multi-block regionalization of urban ethnic settlement concentrations at the subtract level; and (2) patterns of land use (including variations in the type and cost of housing), where the ethnic groups involved differed in their economic resources. Tract boundaries reveal very little of these patterns. Within ethnically differentiated tracts, whites usually lived in single-family houses in higher-status blocks, and Latinos typically were found in apartment buildings in lower-status blocks, but Asians and blacks varied from tract to tract in their type of housing and relative status compared to the other groups.

\section{ADDITIONAL FACTORS BEHIND INTRA-TRACT PATTERNING}

Field investigation of sampled tracts with the greatest block-level ethnic differentiation provided many more examples of the role of differences in housing type and cost as factors in ethnic differentiation. In addition, we found other cases where discussion with local residents suggested that some two- and three-block ethnic clusters were the result of chain migration and the voluntary clustering of a specific immigrant group. Because we were not able to investigate those patterns sufficiently, we restrict our coverage in the following section to more easily observable sources of block-level differentiation that have not yet been discussed.

\section{Hill Sites}

Terrain was sometimes the basis for internal economic and ethnic differentiation (see Meyer, 1994). Tracts in two areas, Glassell Park and nearby Mt. Washington, have long contained both Latinos and whites. In the center of both tracts are hills, accessible by narrow winding roads leading to custom-built homes on small lots. Because such homes are more expensive than those on the flatter lands, and because whites have been wealthier than Latinos, whites dominated the hills while Latinos were more numerous on the flatter lands. This pattern was confirmed in both tracts by the significance of block-level correlation of percentage Mexican origin with median home value.

In another tract in the generally low-income area of Pacoima, the three blocks sharply distinguishable by their higher percentage black were all on a hill and part of relatively new upper-middle-income housing. These blocks contrasted with the lower-income, predominantly Latino population in the flatland blocks below. 


\section{Special Housing}

The role of government in developing and subsidizing housing is evident in the block differentiation of some tracts. Our sampled tracts did not include any of the large public housing projects built in the 1940 s and 1950s, which have been shown to be a source of increased tract-level segregation in some cities (Massey and Kanaiaupuni, 1993). However, they did include three tracts whose internal ethnic patterning was related to the presence of large, privately owned apartment buildings where the rent of low-income tenants was paid partly by the federal government through Section 8 of the 1974 Housing and Community Development Act. According to resident managers, these Section 8 apartments were ethnically differentiated from the surrounding area because members of one or two ethnic groups dominated the waiting lists as a result of greater effort and persistence.

This factor explains the presence of 276 elderly Koreans clustered in one renovated apartment building in the old part of L.A.'s Downtown, where they represent $39 \%$ of the total tract population (Thompson, 1992). Similarly, the 434 Samoans counted in three blocks of a tract in Compton all lived in the federally subsidized Park Village apartments, whose 13-page waiting list was composed almost exclusively of Samoans (McKenzie, 1992). Government-assisted new housing also was part of the reason for the high level of differentiation of Japanese within a tract near Downtown (Community Redevelopment Agency, 1990). There, the three large modern apartment complexes (two of which have been rent subsidized through Section 8) are almost entirely occupied by Japanese tenants. Two blocks away, but within the same tract, is the poor, homeless, racially mixed population in and near the shelters of Skid Row.

In a few other cases, a high level of ethnic differentiation was related to the presence of retirement centers or mobile home parks. In one tract within the highly Latino area of East Los Angeles, block-level differentiation was completely the result of a very high percentage of non-Hispanic whites among the few hundred elderly residents in an expensive and beautifully maintained nursing home. Also, mobile home parks were associated with significantly higher percentages of whites in two tracts that were mostly Latino. Ethnic differences in age structure may have been a factor in the ethnic differentiation, because one of these parks had restricted its residents to the elderly, who were much more apt to be whites than Latinos.

\section{CONCLUSIONS}

Our analysis found that $48 \%$ of the blocks within 300 sampled census tracts showed greater variation in ethnic percentages than could be expected as a result of random factors. This is not surprising, considering the difficulty of delineating tract boundaries around homogeneous areas and the likelihood of ethnic population shifts since the time of census-tract delineation.

Because intra-tract ethnic differentiation was so common and blocks are the smallest areal unit for which ethnic numbers are easily available, describing ethnic distributions or measuring segregation in terms of tracts means that a portion of the distribution or the segregation remains hidden. Thus, block-level ethnic data are preferable for mapping and measuring residential segregation. This point also was made many years ago by Taeuber and Taeuber (1965) and was supported more 
recently by Lasus and Falk (1990), who demonstrated major problems in the use of tracts for comparative measurement of racial segregation in different cities.

On the other hand, only about half of sampled census tracts contained significant non-random ethnic differentiation by blocks. This means that block-level differentiation is not ubiquitous and that many tracts show a level of areal homogeneity that might not be expected, considering the processes of tract definition, urban change, and residential mobility. On balance, census tracts remain useful areal units, although they do miss significant ethnic distributional details in certain situations.

With respect to ethnic differences in block-level differentiation, Cambodians had the greatest block-level differentiation and blacks, Koreans, Samoans, and Vietnamese generally were more differentiated than other groups. Tracts sampled for non-Hispanic whites and people of Mexican origin showed low to average levels of differentiation. However, results for groups varied according to whether the group represented a very low or a moderate percentage within the total tract population.

Tracts that were significantly uneven were more likely to be located in broad zones of economic and ethnic transition, especially those between major black, Japanese, Korean, and Latino settlement areas. Consistent with this were results from correlation analysis, which indicated that blacks and Latinos had greater block-level differentiation in tracts where their incomes were higher, whereas Koreans and Japanese were more differentiated in their lower income tracts. In highly differentiated tracts, whites typically were found in higher-status blocks that generally contained single-family houses; people of Mexican origin (Latinos) most commonly lived in apartment buildings in lower-status blocks; and the housing and relative status of Asians and blacks was more variable.

Because ethnic groups differed in the timing of their arrival and their economic resources, patterns of intra-tract differentiation often reflected the distribution of housing types and prices within tracts. In a few cases, this was related to terrain, in that the more expensive hill sites were dominated by different groups than the surrounding flat lands. Block-level differentiation also occasionally resulted from the presence of government-subsidized apartments or other special housing, such as a mobile home park or retirement center.

The evidence in support of block differences in housing characteristics as an explanation for intra-tract differentiation was much clearer and more common than was evidence suggesting block-level ethnic neighborhoods created through selfselection or discrimination. Spatial patterns associated with these latter processes, however, may be more evident at still larger scales, such as portions of blocks or individual apartment buildings. Intra-tract differentiation was of much less significance within large areas of relatively homogeneous housing, and in such a setting even underlying tensions between blacks and Latinos in a poor area did not result in ethnically differentiated blocks within tracts.

These results do not imply that the census tract as an areal unit is not generally satisfactory. Rather, they suggest that users should realize that census tracts are especially likely to mask internal ethnic patterning in areas where local ethnic groups differ in their economic resources available for housing, in multi-tract transition zones between larger ethnic and economic settlement areas, and in tracts that contain substantial differences between blocks in terms of housing type and price. 


\title{
NOTES
}

\begin{abstract}
'Research expenses were covered by a grant from the School of Social and Behavioral Sciences at California State University, Northridge. Greg Lipton, formerly of Los Angeles City's Community Development Department, loaned us the STFIB computer tapes that contained block data. Howard Lasus, Michael White, Bill Clark, and an anonymous reviewer provided helpful comments on earlier versions of the manuscript. We thank all of the above for their assistance.

2Foxbase Pro software was used on a Macintosh IIci computer to extract the block data from STF1B computer tapes. Latitudes and longitudes of the blocks, as well as associated census data, were organized in Excel 4.0 software and transferred to the Atlas Pro mapping program. The graduated symbol maps we produced were saved as PICT files and read into Canvas 3.0 for finishing. Finished maps were saved as postscript files and imported into Adobe Illustrator 5.0. These files then were converted to 133-line negatives on a Linotronics 300 imagesetter.
\end{abstract}

\section{LITERATURE CITED}

Allen, J.P. and Turner, E., forthcoming, Ethnic diversity and segregation in the new Los Angeles. In C. Roseman, G. Thieme, and H.D. Laux, eds., EthniCity: Geographical Perspectives on Ethnic Change in Modern Cities. Lanham, MD: Rowman \& Littlefield.

Bartlet, D., Elesh, D., Goldstein, I., Leon, G., and Yancey, W., 1987, Islands in the stream: Neighborhoods and the political economy of the city. In I. Altman and A. Wandersman, eds., Neighborhood and Community Environments. New York: Plenum Press.

Cadwallader, M., 1988, Urban geography and social theory. Urban Geography, Vol. 9, 227-251.

Chen, W-H. C., 1952, Changing Socio-Cultural Patterns of the Chinese Community in Los Angeles. Unpublished Ph.D. dissertation, Department of Sociology, University of Southern California.

Clark, W.A.V., 1992, Residential preferences and residential choices in a multiethnic context. Demography, Vol. 29, 451-466.

Community Redevelopment Agency, City of Los Angeles, 1990, Little Tokyo Redevelopment Project: Biennial Report, 1988-1990. Los Angeles: Community Redevelopment Agency.

Cortese, C.F., Falk, R.F., and Cohen, J.K., 1976, Further considerations on the methodological analysis of segregation indices. American Sociological Review, Vol. $41,630-637$.

Cowgill, D.C. and Cowgill, M.S., 1951, An index of segregation based on block statistics. American Sociological Review, Vol. 16, 825-831.

Cybriwsky, R.A., 1978, Social aspects of neighborhood change. Annals of the Association of American Geographers, Vol. 68, 17-33.

Doeppers, D.F., 1967, The Globeville neighborhood in Denver. Geographical Review, Vol. 57, 506-522.

Duncan, O.D. and Duncan, B., 1955, A methodological analysis of segregation indexes. American Sociological Review, Vol. 20, 210-217.

Falk, R.F., Cortese, C.F., and Cohen, J., 1978, Utilizing standardized indices of residential segregation: Comment on Winship. Social Forces, Vol. 57, 713-716. 
Fotheringham, A.S. and Wong, D.W.S., 1991, The modifiable areal unit problem in multivariate statistical analysis. Environment and Planning A, Vol. 23, 1025-1044.

Harrison, R.J. and Weinberg, D.H., 1992, Racial and ethnic residential segregation in 1990. Paper presented to the Population Association of America Annual Meeting, Denver, CO, April.

Hoyt, H., 1939, The Structure and Growth of Residential Neighborhoods in American Cities. Washington, DC: U.S. Federal Housing Administration.

James, D.R. and Taeuber, K.E., 1985, Measures of segregation. In N.B. Tuma, ed., Sociological Methodology, 1985. San Francisco: Jossey-Bass Inc., 1-32.

Johnson, J.H., Jr. and Oliver, M.L., 1989, Interethnic minority conflict in urban America: The effects of economic and social dislocations. Urban Geography, Vol. 10, 449-463.

Lasus, H.A. and Falk, R.F., 1990, How generalizable are findings based on census tracts?: Problems measuring residential segregation using the index of dissimilarity with census tracts, city blocks, and grids. Paper presented to the American Sociological Association, Washington, DC, August.

MacDonald, J.S. and MacDonald, L.D., 1964, Chain migration, ethnic neighborhood formation, and social networks. Milbank Memorial Fund Quarterly, Vol. 42, 82-97.

McKenzie, M., 1992, Manager of Park Village, Compton, California. Interview, February.

Massey, D.S., 1978, On the measurement of segregation as a random variable. American Sociological Review, Vol. 43, 587-590. 1985, Ethnic residential segregation: A theoretical synthesis and empirical review. Sociology and Social Research, Vol. 69, 315-350. and Denton, N.A., 1988, The dimensions of residential segregation. Social Forces, Vol. 67, 281-315. and 1989, Hypersegregation in U.S. metropolitan areas: Black and Hispanic segregation along five dimensions. Demography, Vol. 26, 373-391. and Kanaiaupuni, S.M., 1993, Public housing and the concentration of poverty. Social Science Quarterly, Vol. 74, 109-122.

Meyer, W.B., 1994, Bringing hypsography back in: Altitude and residence in American cities. Urban Geography, Vol. 15, 505-513.

Myers, J.K., 1954, Note on the homogeneity of census tracts: A methodological problem in urban ecological research. Social Forces, Vol. 32, 364-366.

Openshaw, S., 1984, The Modifiable Areal Unit Problem. Norwich, England: Geo Books, Concepts and Techniques in Modern Geography, No. 38.

Suttles, G.D., 1968, The Social Order of the Slum: Ethnicity and Territory in the Inner City. Chicago: University of Chicago Press.

Taeuber, A.F., 1978, A practitioner's perspective on the index of dissimilarity. American Sociological Review, Vol. 41, 884-889.

Taeuber, K.E. and Taeuber, A.F., 1965, Negroes in Cities: Residential Segregation and Neighborhood Change. Chicago: Aldine Publishing Company.

Thomas, W.I., Park, R.E., and Miller, H.A., 1921, Old World Traits Transplanted. New York: Harper Brothers.

Thompson, C., 1992, Administrator for S.K. Management Co., Los Angeles. Interview, July. 
Tobin, G.A., ed., 1987, Divided Neighborhoods: Changing Patterns of Racial Segregation. Newbury Park, CA: Sage Publications.

Turner, M.A., Struyk, R.J., and Yinger, J., 1991, The Housing Discrimination Study: Synthesis. Washington, DC: The Urban Institute and Syracuse University.

U.S. Bureau of the Census, 1985, Guidelines for Delineating Census Tracts and Block Groups. 1990 Geographic Area Programs, 1990 Census of Population and Housing. Washington, DC: The U.S. Bureau of the Census. 1991 a, 1990 Census of Population and Housing. Summary Tape File IA, IB (California), and Technical Documentation. Washington, DC: The U.S. Bureau of the Census.

$1991 \mathrm{~b}, 1990$ Census of Population and Housing. Summary Tape File $3 A$ (California). Washington, DC: The U.S. Bureau of the Census.

White, M.J., 1986, Segregation and diversity measures in population distribution. Population Index, Vol. 52, 198-221.

1988, The Segregation and Residential Assimilation of Immigrants. Washington, DC: The Urban Institute, Policy Discussion Paper.

Winship, C., 1977, A revaluation of indexes of residential segregation. Social Forces, Vol. 55, 1058-1066.

1978, The desirability of using the index of dissimilarity or any adjustment of it for measuring segregation: Reply to Falk, Cortese, and Cohen. Social Forces, Vol. 57, 717-720.

Zorbaugh, H.W., 1929, The Gold Coast and the Slum: A Sociological Study of Chicago's Near North Side. Chicago: University of Chicago Press. 


\section{Appendix 1.-Index of Dissimilarity and Its Adjustment}

There is a large body of literature on the measurement of different dimensions of residential segregation by various statistics (e.g. Duncan and Duncan, 1955; James and Taeuber, 1985; White, 1986; Massey and Denton, 1988), but the index of dissimilarity $(D)$ is the appropriate statistic for measuring the unevenness in ethnic proportions between areal units.

$$
D=\sum_{i=1}^{k} \frac{T_{i}\left|P_{i}-P\right|}{2 T P(1-P)}
$$

In this case, $k$ equals the number of blocks in any tract whose unevenness is being measured, $P_{i}$ is the proportion ethnic in block $i, P$ is the proportion ethnic in the tract, $T_{i}$ is the total population of block $i$, and $T$ is the total population of the tract (Winship, 1977). Ethnic proportions were compared to the proportions non-ethnic, i.e., not in the group in question.

Values of $D$ range from 1.0, indicating complete unevenness (the population of all blocks is either $100 \%$ or $0 \%$ of the ethnic group in question), to 0.0 , indicating that all blocks share the same ethnic percentage as the tract average. $D$ can be interpreted as the proportion of a tract's specific ethnic population that would need to move to other blocks in order to achieve an even proportion of that ethnic population across all blocks in the tract.

The most common criticism of $D$ has been that comparisons between cities or metropolitan areas can be distorted by variations between those areas in ethnic proportions and by small population numbers in the areal units measured. We overcame those problems by our adjustment to eliminate the random portion of observed unevenness.

There has been much discussion among sociologists concerning the best theoretical and practical technique for making this adjustment (Cortese, Falk, and Cohen, 1976; Taeuber and Taeuber, 1976; Winship, 1977, 1978; Falk, Cortese, and Cohen, 1978; Massey, 1978), but no consensus has emerged. For this reason, we followed the specific suggestion of Winship (1977) and calculated for each of our sampled tracts expected values of $D$ using the normal approximation to the binomial distribution:

$$
E(D)=\frac{1}{\sqrt{2 \pi T_{i} P(1-P)}} .
$$

In this case, $T_{i}$ is the average population per block within a tract.

The expected value of $D$ for each tract then was subtracted from $D$ and the remainder standardized by division by $1-E(D)$. The result was an Adjusted $D$ whose values were not affected by variations in ethnic proportions in tracts or the population size of blocks:

$$
\text { Adjusted } D=[D-E(D)] /[1-E(D)] \text {. }
$$

Our results should be viewed as approximate, rather than precise, indicators the extent of intra-tract ethnic differentiation because of non-random settlement processes, for three reasons: (1) computer allocation of missing race and Hispanic-origin responses may have introduced errors in block-level data, (2) the binomial approximation may not have been the mathematically ideal mechanism for adjustment in these situations in which blocks differed in their population numbers, and (3) the Adjusted $D$ for many tracts was very close to the value required for significance. 